Research Article

\title{
Intelligent Integrated Community Model for Ethnic Minority Areas Using Data Analysis and Machine Learning
}

\author{
Xiaoxue Liu \\ School of Architecture and Art Design, Hebei University of Technology, Tianjin 300130, China \\ Correspondence should be addressed to Xiaoxue Liu; 2006011@hebut.edu.cn
}

Received 21 January 2021; Revised 18 February 2021; Accepted 26 February 2021; Published 9 March 2021

Academic Editor: Muhammad Babar

Copyright (C) 2021 Xiaoxue Liu. This is an open access article distributed under the Creative Commons Attribution License, which permits unrestricted use, distribution, and reproduction in any medium, provided the original work is properly cited.

\begin{abstract}
The intelligent community has become a technological trend with the continuous development of China's Internet economy and the continuous improvement in community cooperative governance. The comprehensive service system in ethnic areas is also one of the reasons for the intelligent community. It plays an important role in community cooperative governance and comprehensive service system construction in ethnic minority areas. This paper briefly analyzes the important opportunities provided by the "wisdom community" for community cooperative governance and comprehensive service system construction in ethnic minority areas. For this purpose, an integrated model for the construction of a "culture sharing cloud system," "public cultural service microplatform," and "interactive end of public cultural service" is proposed. The mode of wisdom community's public culture is utilized in the proposed integrated model. Our proposed model puts forward some countermeasures to accelerate the construction of infrastructure, innovate the digital service system of public culture, and optimize the internal organizational structure of the government. The existing datasets are analyzed to design the proposed model. Machine learning techniques are utilized to design the proposed intelligent community system. The proposed model overcomes the existing communication bottleneck for the public cultural service in ethnic minority areas and accelerates the realization of community coordination governance and the optimization of the comprehensive service system. It also improves the modernization level of minority areas. Finally, the effectiveness of the proposed model is highlighted.
\end{abstract}

\section{Introduction}

In recent years, the construction of public culture in minority areas in China has made great achievements under the leadership of the party. Along with the basic aspects of China's economy, new changes have taken place, and the construction and development of public culture in ethnic areas has also entered a new stage. The third Plenary Session of the 18th CPC Central Committee proposed to "promote the innovation of the cultural system and mechanism" to "adhere to the people-centered work orientation, persist in putting social benefits first, and integrate social and economic benefits." To stimulate the vitality of the national culture as the central link, further deepen the reform of the cultural system. "At present, with the continuous improvement of the cultural quality of the masses and the wide application of network technology, the public's demand for public culture has also changed a lot." How to make full use of the technological advantages of the Internet, give full play to the role of the Internet in the optimization and integration of cultural resources allocation, and integrate the innovative achievements of the Internet with public cultural services in depth should be studied. Breaking through the existing communication bottleneck for the public cultural service in the minority areas, accelerating the realization of modernization has brought great opportunities [1]. With the continuous development of the Internet economy in our country and the continuous improvement of the community cooperative governance and comprehensive service system in ethnic areas, "intelligent community" has become a trend of development. It also plays an important role in community cooperative governance and comprehensive service system construction in ethnic minority areas [2].

The community cooperative governance and comprehensive service system is dominated by government organizations and investment, supplemented by the participation 
of social forces, and is mainly used to serve and improve the quality of farmers. A comprehensive system for providing public cultural services products and services to farmers. It mainly includes the rural public cultural facilities system, the public cultural network system, the public welfare cultural service system, the public culture management system, and so forth [3-5]. The construction of community cooperative governance and comprehensive service system is an important content of the construction of new socialist countryside and an important embodiment of the implementation of the scientific concept of development and the construction of a harmonious socialist society. At present, the construction of community cooperative governance and comprehensive service system in ethnic minority areas is not perfect, the rural cultural infrastructure is relatively weak, the funds are insufficient, and the grass-roots cultural talents are lacking [6]. To perfect the community cooperative governance and comprehensive service system in ethnic minority areas, we should make great efforts to innovate the construction mode of community cooperative governance and comprehensive service system, perfect the talent training system, and construct the investment mechanism combining government and social participation [7], strengthening cultural infrastructure construction and other aspects of work. The socialization of urban community public service in minority areas is an effective way to realize the harmonious promotion of urbanization and urban public service. Through the construction of the intelligent community, we can give full play to the optimization and integration of the Internet in the allocation of cultural resources and deeply integrate the innovative achievements of the Internet and the intelligent community with the public cultural services.

There is a need of an intelligent centralized system to promote the process of socialization of public services on the basis of correctly understanding the nature of public goods and public services. In the process, it is necessary to improve the effective degree of community residents' public service demand expression, improve the community residents' public service demand expression mechanism, strengthen community cultural construction by establishing a strong community spirit, and reorganize community resources to pursue public interests. The centralized system can be based on the available data that define the responsibility of the government. Under the background of "intelligent community," this article constructs the community cooperative governance and integrated service system in ethnic areas. The paper further describes the system based on the available data by utilizing them with machine learning algorithms. It analyzes briefly the important opportunities provided by the "intelligent community" for the construction of community cooperative governance and comprehensive service system in ethnic areas. It also puts forward the construction of "culture sharing cloud system," "public cultural service microplatform," and "interactive end of public cultural service" by using the mode of "wisdom community public culture." This paper puts forward some countermeasures to accelerate the construction of infrastructure, innovate the digital service system of public culture, and optimize the internal organizational structure of the government [8-10].
The proposed model puts forward some countermeasures to accelerate the construction of infrastructure, innovate the digital service system of public culture, and optimize the internal organizational structure of the government. The existing datasets are analyzed to design the proposed model. Machine learning techniques are utilized to design our proposed intelligent community system. The proposed model overcomes the existing communication bottleneck.

\section{Community Cogovernance and Comprehensive Service System}

At current, the government pays more consideration to the effort of community social facility in minority zones. Due to the encouragement of geographical aspects, the deployment rate of community cultural services and resources in minority areas is low. Therefore, there is a need of an intelligent system for the community for ethnic areas.

2.1. Intelligent Community Construction. The "intelligent community" can greatly promote the innovation of the public cultural service mechanism in ethnic minority areas and use the Internet to carry out digital cultural services, from physical services to virtual services and, at the same time, in the process of constructing the service system, improve the service system through big data and improve the pertinence and effectiveness of public cultural services in ethnic areas. Simultaneously, the full use of the thinking of an "intelligent community" can greatly promote the mode of public cultural service in ethnic areas of our country and improve the efficiency of public cultural service in ethnic areas [11]. Governments at all levels may, through the combination of the Internet and cultural departments and based on the national public cultural digital support platform, establish a grass-root public digital cultural service management platform in ethnic minority areas and formulate corresponding platform construction, management, and application standards. To realize the integrated intelligent management of the basic level public cultural service network facilities and the project of benefiting the people [12], the architecture of the smart community can be divided into four levels: the perception level, the network level, application level, and the terminal level. The sensing layer uses sensing devices to collect data and monitor devices. The network layer is used to transmit information in the smart community. The application layer provides various services for residents, and the terminal layer allows users to use various services of the intelligent community through various intelligent terminals. The architecture of the smart community is shown in Figure 1.

2.1.1. Perception Layer. The sensory layer is used for the meter set of data. Perceptual devices use sensing devices such as gateways, sensors, and modules to fully inspect and collect real-time information about the infrastructure. The sensing layer equipment of the infrastructure management system is 
a variety of instruments and gateways. The meters are responsible for collecting residents' water, electricity, and gas usage information and transmitting the information to the gateway. The gateway transmits the data to the network layer. Administrators can fully understand the usage of water, electricity, and gas in real time through water, electricity, gas, and other information and realize a fully aware function.

2.1.2. Network Layer. Perceived devices, application servers, and smart terminals are connected at the network layer, and various subsystems are brought together at the network layer to form a unified smart community service platform. The network and fourth-generation mobile communication technologies will play a catalytic role in the development of smart communities. Besides, they include sensor networks and wireless networks. The infrastructure management system will use acquisition servers and networks as the network layer for data transfer.

2.1.3. Application Layer. The function of the application layer is to process the sensed data and provide people with various application services, including infrastructure management, smart home, community security, billing services, e-commerce, telemedicine, and remote monitoring. Among them, infrastructure management includes elevator management, street lamp management, instrument management, drainage management, monitoring, and management. The infrastructure management system processes the data collected by the instrument to provide users with instrument management services and payment services, which makes it easier for administrators to manage instruments and other equipment and, at the same time, makes it easier for people to pay.

2.1.4. Application Layer. Community residents use terminal devices to use smart community services. Terminal equipment includes mobile phones, home smart terminals, smart remotes, and tablet computers. In the infrastructure management system, people can use mobile phones and carry out payment and inquiries.

2.2. National Public Culture Service System Promotion in the Wisdom Community. The wisdom community promotion is the key to the success of the national public cultural service system. The detailed description of the required promotion components is discussed in the upcoming sections.

2.2.1. Culture Sharing Cloud. Integrate superior resources and establish a "culture sharing cloud" system in ethnic areas. Cloud computing, big data, and mobile Internet are today's three hot topics of information technology. In combination with the latest practice of public digital culture and the development trend of information technology, we can build a "culture sharing cloud" system in minority areas with all-round coverage, multiterminal access, cross-platform, and multichannel distribution. When the mobile terminal installs the corresponding software and browses the corresponding website, it can understand a series of cultural activities information anytime and anywhere, enjoy the one-stop public cultural service, and effectively solve the information asymmetry of the public cultural activities. Facilities resource utilization rate is not high [13].

2.2.2. Microplatform. Activate the market potential and establish the microplatform of public cultural service in minority areas. The Internet has a full impact on the world today, and all industrial areas will be redefined, including cultural industries. Zhoushan City in Zhejiang Province, with the help of the Taobao model, launched the "Amoy Culture Network" to let cultural teams of all kinds produce cultural products to act as "sellers" and organizations or groups of consumers' cultural products to act as "buyers." In addition to placing orders, buying, and selling, you can also evaluate services to build a freely chosen platform between buyers and sellers. Ethnic regions have very rich traditional cultural resources, can rely on "Zhoushan mode," through the integration of resources to build a new demand-oriented cultural supply and demand docking network platform, draw lessons from the Taobao operation model, relying on the Internet, and set up an efficient and convenient service platform for government, market, and masses.

2.2.3. Information Asymmetry. To set up the interactive end of public cultural service in ethnic areas, "information asymmetry" has always been a difficult problem for community coordination governance and comprehensive service system construction in ethnic minority areas: on the one hand, people always say that they do not know what cultural activities are being held; on the other hand, cultural venues often complain about lack of popularity. Similarly, some local governments invest a lot of manpower and material resources in cultural service projects, and the public may not like them. This requires the government to attach great importance to the interactive construction of public cultural services. It is necessary to use the Internet as an important platform for the investigation, collection, and analysis of the cultural needs of the masses, to establish a microplatform for interaction with the masses in ethnic areas, and to publish some cultural resources information through government portals, official WeChat, Weibo, and other interactive terminals. Let the masses truly express their cultural needs and meet the needs of the masses.

\section{Path Choice of Proposed System in Minority Areas}

There are several options to choose the best one. We have proposed a mechanism to choose the right path. 
3.1. Strategic Significance of Proposed System Construction in Ethnic Areas. The 17th Session of the Third Plenary Session of the Communist Party of China (CPC) adopted the Decision of the Central Committee of the Communist Party of China on several important issues concerning the development of rural reform and further called for the acceleration of the development of rural public undertakings and the improvement in the overall progress of the rural society [14]. Firstly, it is an important content of building a new socialist countryside. The production and development, living allowance, township wind civilization, village cleanness, and management democracy are the general requirements of the construction of socialist new countryside. The core of the new socialist countryside construction is to strengthen the construction of rural culture [15]. The community management structure is shown in Figure 2.

Secondly, it is an unavoidable requisite to completely execute the scientific growth and shape a harmonious socialist harmonious society $[16,17]$. It is necessary to accelerate the construction of community cooperative governance and comprehensive service system, realize good, maintain good, develop the basic cultural rights and interests of the masses of peasants, reflect the scientific development of the cultural undertakings, promote the comprehensive integration and effective utilization of various cultural resource elements, such as government resources, social resources, service resources, and management resources, and promote the comprehensive, coordinated and sustainable development of culture and society.

Thirdly, it is an essential obligation to attain the shared agreement of the peoples and the shared success and growth. It is also a necessary strategy of the Central Government to provision the fast-tracked growth of ethnic minorities and ethnic areas [18]. The ethnic minorities require an urgent action in the context of COVID 19 [19]. The National unity is the fundamental guarantee for maintaining national unity and realizing the common development of all peoples. The only development in the minority areas can be stabilized. The culture is the spiritual power of strengthening unity and urging people to move forward. The cultural level is also lower than that of the central and eastern regions and ethnic areas. It is possible to develop a public cultural service system, foster the comprehensive quality of the masses of the masses, and train new citizens who can meet the requirements of the socialist market economy, and it is an effective way to promote the common prosperity of the peoples $[20,21]$. It is a strong link between the people of our country and the people of our country to work together for common prosperity and development. It is an important role to build a public cultural service system, develop rich and colorful and unique ethnic cultures, and play an important role in strengthening the unity and cooperation of all peoples and realizing the common prosperity of the peoples.

3.2. Improvement of Proposed System in Ethnic Areas. The improvement of the Community Cooperative Governance and Integrated Service can be done in the following ways.
3.2.1. Establish and Improve the Elementary System of Rural Public Culture in Ethnic Areas. The establishment and improvement of the elementary system of rural public culture in ethnic areas are required to improve the system for the ethnic areas. The construction of cultural infrastructure in the minority areas has been greatly improved in recent years, but the cultural infrastructure is still relatively backward compared with the eastern region. Therefore, Party and Government must attach great importance to the improvement of public cultural infrastructure.

3.2.2. Improving Talent Training System. The talent training system and its strengthening are also required in the construction of rural cultural teams in ethnic areas. First, we should strengthen the management of the existing talents, use the existing talents, improve the treatment, and devote themselves to the development of the cultural undertakings in the minority areas. Secondly, we should strengthen the cultivation of the new people, build the endogenous mechanism of the rural public cultural services, and cultivate the new rural cultural subjects. Most of the ethnic areas are located in remote areas with inconvenient traffic, poor information, underdeveloped economy, strong measures are required to meet the needs of the people's spiritual and cultural needs in these areas, and the training of the cultural information resources is in sharing engineering talents, the introduction of professional technical personnel, and the organization of a high-level resource construction, software development, and website maintenance technical backbone team; thirdly, in the face of the deterioration of the cultural environment of minority nationality, the cultivation of cultural construction management talents, such as radio and television and library and information, is mandatory.

3.2.3. Innovative Community Cooperative Governance and Integrated Service System Construction Model. In the construction of community cogovernance and comprehensive service system, the mode of innovation must be innovated. Firstly, it is necessary to fundamentally change the development mode with the external one-way input as the main and to focus on the integration of the advanced culture of socialism with the folk culture of the excellent national folk culture in our country.

\subsubsection{Input Mechanism of the Combination of Government} and Social Participation. The shortage of funds is the most direct reason for the lag of rural cultural development in the minority areas. The abundant capital investment is the basic guarantee for the construction of public culture in rural areas. On the one hand, the government should increase the input of rural public culture funds and, on the other hand, should establish scientific and institutionalized investment mechanisms to form an investment safeguard mechanism of a virtuous circle. To encourage the multi-input of community cooperative governance and comprehensive service system, we should encourage the multi-input of community cooperative governance and comprehensive service system, 

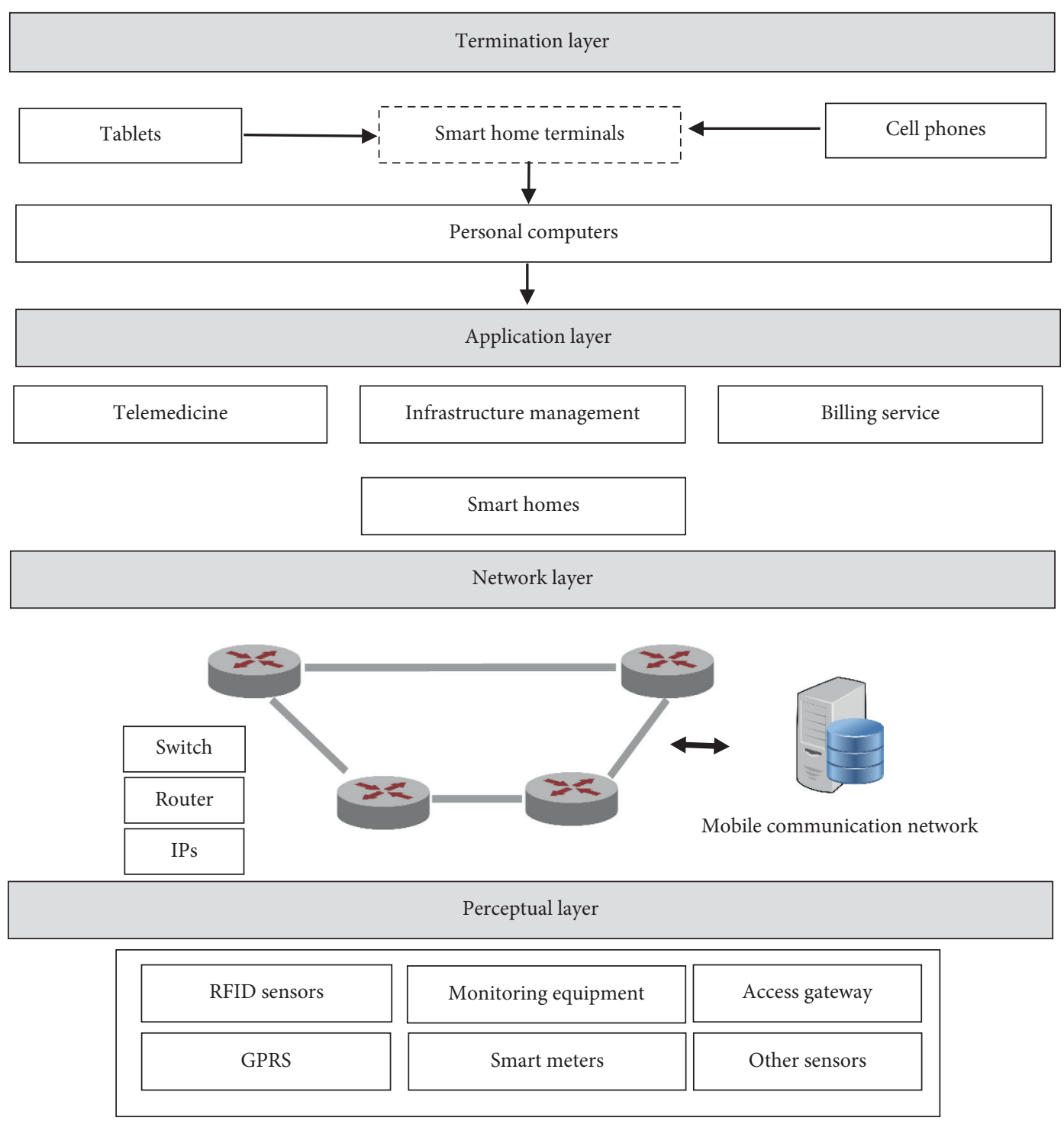

FIGURE 1: Smart and intelligent community architecture.

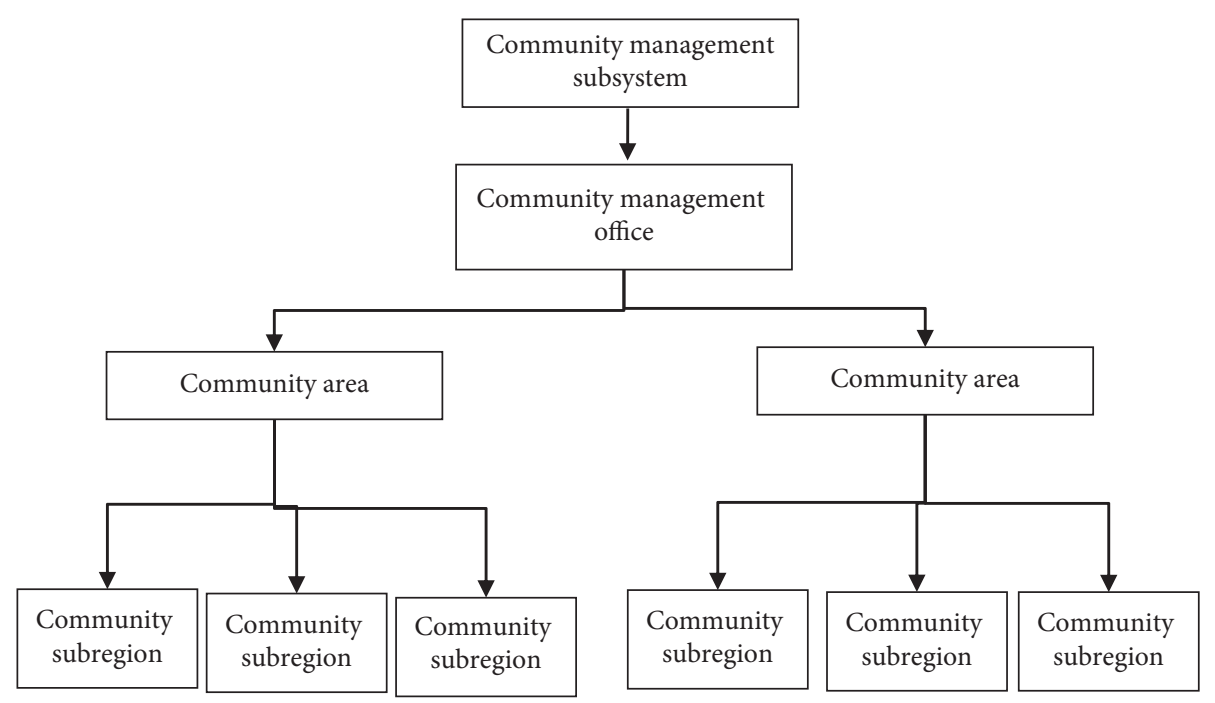

FIGURE 2: Structural diagram of smart community management. 
TABLE 1: Comparison of existing and proposed systems.

\begin{tabular}{lc}
\hline Existing system & Proposed system \\
\hline Does not support decision-making & Support decision-making \\
Not adaptable & Adaptable \\
Static & Dynamic \\
Manual services & Digital services \\
Not optimized & Optimized \\
Does not provide training & Include training system \\
Only tradition elementary services & Improved elementary services \\
Does not support telemedicine & Support telemedicine \\
Does not support smart services & Support smart services \\
\hline
\end{tabular}

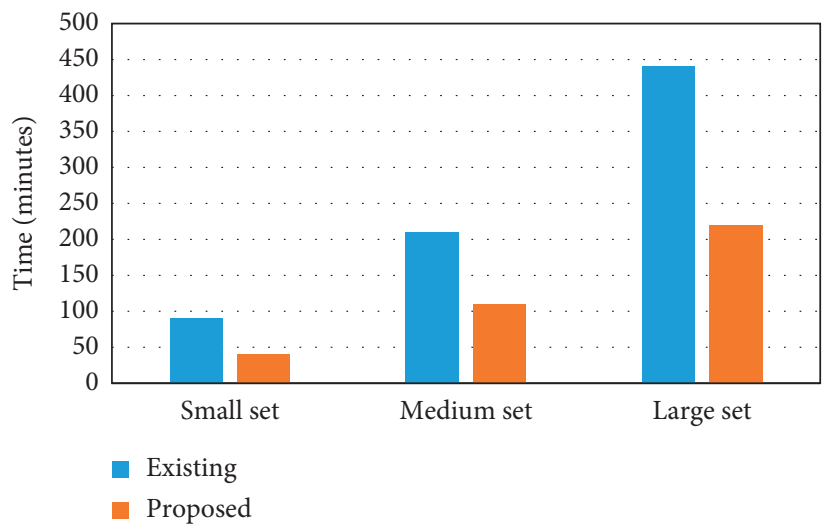

FIgURe 3: Comparison of execution time.

cultivate the pluralism of the main body, encourage the community to participate in the construction of rural public culture, and implement and perfect the preferential policies for the donation and sponsorship of rural cultural undertakings.

\section{Countermeasures and Suggestions}

The countermeasures and suggestions of "Wisdom Community" are also required for the Construction of Community Coordination and Integrated Service systems in minority areas. This mechanism highlights the effectiveness.

4.1. Multiple Investors and Internet Infrastructure. In this section, we need to create multiple investors and speed up the construction of Internet infrastructure. The construction of a public cultural service system in minority areas needs to gradually adjust the investment means of the government to the end, actively play the role of folk capital, broaden the channels of investment in public cultural services, and establish. The multi-investment mechanism is constructed based on government investment and supplemented by social multichannel investment. Ethnic regions have unique cultural and geographical advantages, and local governments can also seek cooperation with the eastern developed provinces to attract folk capital and other ways, to construct the diversification of investment subjects, to mobilize social forces to participate widely, and to contribute to the infrastructure construction in minority areas.
4.2. Cultural Development Modernization and Digital Service System Innovation. We need to speed up the modernization of cultural development and innovate the digital service system of public culture. By the end of December 2017, China's Internet users had reached 1029 million, including 820 million mobile phone users, according to CNNIC, the China Internet Information Center. Mobile Internet has become the most important way for people to obtain cultural information. The construction of public culture in minority areas can use modern science and technology to integrate public cultural services, promote the public digital cultural service network, and create a digital service platform covering urban and rural areas, with the Internet as the main service means. Local governments can share cultural resources as a whole, strengthen digital processing and integration of public cultural information and products in minority areas, and develop and produce traditional cultural information and satellite data for the needs of ethnic minorities. Resources especially focus on the intangible cultural heritage and minority languages and other traditional cultural resources "digital” protection.

\subsection{Internal Structure Optimization and Cultural Resources} Utilization. Finally, we need to optimize the internal structure of the government and coordinate and integrate the utilization of cultural resources. The construction of a modern public cultural service system involves the production and distribution of cultural products. The whole system design including management and resource 
guarantee system must integrate the power of government and society and break through the system limitation of trade barrier and public resource system. The establishment of a coordination mechanism for the construction of a public cultural service system is a strong organizational guarantee for the construction of an "intelligent community public culture" in ethnic areas. The governments of ethnic minority areas should take the opportunity of deepening the reform of the cultural system to set up a cultural sector-led, economic, propaganda, financial, radio, and television industry. The coordinating body of sports and other departments is responsible for the work of "public cultural service in intelligent community" and responsible for organizing, planning, coordinating, carrying out, examining, coordinating regional cultural resources, and speeding up the formation of the scientific and effective macrocultural management system. Through a sound and perfect organizational system, the construction of "public culture in intelligent communities" should be promoted into a new stage of development so that the broad masses of the people in minority areas can share the fruits of reform and development and enrich the cultural life. The comparison of the proposed system based on the Intelligent Community Model with the existing system is depicted in Table 1. The comparison of process execution time with the existing system is also provided in Figure 3 regarding different classes of the processes (e.g., small set, medium set, and large set). The small process set is up to 10 processes, the medium process set includes $10-20$ processes, while the large set is having around 20-30 processes.

\section{Conclusions}

This article proposes an intelligent system model to realize the socialization of public services in minority areas. The cooperative governance and integrated service system in minority areas is an important process. The proposed model is the integration on the construction of "culture sharing cloud system," "public cultural service microplatform," and "interactive end of public cultural service." The existing datasets are analyzed to design the proposed model. Machine learning techniques are utilized to design the proposed intelligent community system. Under the background of "intelligent community," it optimizes the construction of community cooperative governance and comprehensive service system in ethnic minority areas, mobilizes social forces to participate extensively, and contributes to the construction of infrastructure in minority areas. The innovative achievements of the Internet and the intelligent communities are deeply integrated with the public cultural services, to serve the public in minority areas. The effectiveness of the proposed model is also highlighted. Besides, it also improves the modernization level of minority areas. The proposed model overcomes the existing communication bottleneck for the public cultural service in minority areas.

\section{Data Availability}

We have already included the analysis data in our manuscript.

\section{Conflicts of Interest}

The author declares that there are no conflicts of interest.

\section{References}

[1] L. Mao, "Practice and thinking of promoting community cooperative governance and comprehensive service system construction," Jiangnan Forum, vol. 11, no. 2, pp. 23-25, 2008.

[2] J. Chen, "On the construction of community synergetic governance and integrated service system in ethnic areas," Guizhou Ethnic Studies, vol. 2, pp. 16-19, 2008.

[3] Z. Xiao, L. Zhu, F. Dongyu, and D. Zhang, "Performance optimization of distributed database aggregation computing," Journal of Computer Applications, vol. 37, no. 5, pp. 12511256, 2017.

[4] J. Han, E. Haihong, G. Le et al., "Survey on NoSQL database," in Proceedings of the 20116th International Conference on Pervasive Computing and Applications, pp. 363-366, IEEE, Piscataway, NJ, USA, May 2011.

[5] J. Han, M. Song, and J. Song, "A novel solution of distributed memory NoSQL database for cloud computing," in Proceedings of the 2011 IEEE/ACIS 10th International Conference on Computer and Information Science, pp. 351-355, IEEE, Piscataway, NJ, USA, May 2011.

[6] H. Kaur and J. Singh, "Improvement in load balancing technique for MongoDB clusters," International Journal of Applied Information Systems, vol. 8, no. 4, pp. 31-35, 2015.

[7] J. Ean and S. Ghemawat, "MapReduce:simplified data processing on large clusters," Communications of the ACM, vol. 51, no. 1, pp. 107-113, 2008.

[8] E. Dede, M. Govindaraju, D. Gunter et al., "Performance evaluation of a MongoDB and Hadoop platform for scientific data analysis," in Proceedings of the 4th ACM Workshop on Scientific Cloud Computing, pp. 13-20, ACM, New York, NY, USA, June 2013.

[9] Y. Liu, Y. Wang, and Y. Jin, "Research on the improvement of MongoDB auto-sharding in cloud environment," in Proceedings of the 20127th International Conference on Computer Science \& Education, pp. 851-854, IEEE, Piscataway, NJ, USA, July 2012.

[10] P. Kookarinrat and Y. Temtanapat, "Analysis of range-based key properties for sharded cluster of MongoDB," in Proceedings of the 2015 2nd International Conference on Information Science and Security, pp. 1-4, IEEE, Piscataway, NJ, USA, December 2015

[11] V. Dyo, S. A. Ellwood, D. W. Macdonald et al., "Wildsensing," ACM Transactions on Sensor Networks, vol. 8, no. 4, pp. 1-33, 2012.

[12] D. Miorandi, S. Sicari, F. De Pellegrini, and I. Chlamtac, "Internet of things: vision, applications and research challenges," Ad Hoc Networks, vol. 10, no. 7, pp. 1497-1516, 2012.

[13] S. K. Chong, M. M. Gaber, S. Krishnaswamy, and S. W. Loke, "Energy conservation in wireless sensor networks: a rulebased approach," Knowledge and Information Systems, vol. 28, no. 3, pp. 579-614, 2011.

[14] L. M. Oliveira and J. J. Rodrigues, "Wireless sensor networks: a survey on environmental monitoring," Journal of Communications, vol. 6, no. 2, pp. 143-151, 2011.

[15] G. Hackmann, F. Sun, N. Castaneda, C. Lu, and S. Dyke, “A holistic approach to decentralized structural damage localization using wireless sensor networks," Computer Communications, vol. 36, no. 1, pp. 29-41, 2012. 
[16] S. Li, "Research on the construction of legal mechanism of socialist harmonious society based on computer simulation," in Journal of Physics: Conference Series, vol. 1544, no. 1, IOP Publishing, Article ID 012200, 2020.

[17] C. P. Pow, "Building a harmonious society through greening: ecological civilization and aesthetic governmentality in China," Annals of the American Association of Geographers, vol. 108, no. 3, pp. 864-883, 2018.

[18] H. Weber, "The educational divide over feelings about ethnic minorities: does more education really lead to less prejudice?" Journal of Ethnic and Migration Studies, vol. 2020, pp. 1-20, 2020.

[19] K. Khunti, L. Platt, R. Ash, and K. Abbasi, "Covid-19 and ethnic minorities: an urgent agenda for overdue action," $B M J$, vol. m2503, 2020.

[20] A. Y. Lo, "Carbon trading in a socialist market economy: can China make a difference?" Ecological Economics, vol. 87, pp. 72-74, 2013.

[21] G. Sigley, "Chinese governmentalities: government, governance and the socialist market economy," Economy and Society, vol. 35, no. 4, pp. 487-508, 2006. 